WellBeing International

WBI Studies Repository

12-1999

\title{
Animal Ethics and Animal Welfare Science: Bridging the Two Cultures
}

David Fraser

University of British Columbia

Follow this and additional works at: https://www.wellbeingintlstudiesrepository.org/acwp_awap

Part of the Animal Studies Commons, Civic and Community Engagement Commons, and the Politics and Social Change Commons

\section{Recommended Citation}

Fraser, D. (1999). Animal ethics and animal welfare science: bridging the two cultures. Applied Animal Behaviour Science, 65(3), 171-189.

This material is brought to you for free and open access by WellBeing International. It has been accepted for inclusion by an authorized administrator of the WBI Studies Repository. For more information, please contact wbisr-info@wellbeingintl.org.

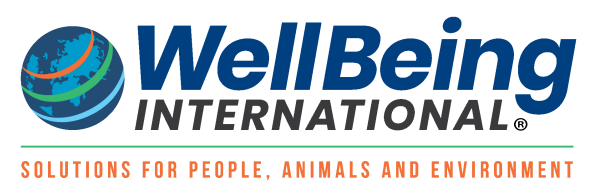




\title{
Animal Ethics and Animal Welfare Science: Bridging the Two Cultures ${ }^{a}$
}

\author{
David Fraser \\ University of British Columbia
}

\section{KEYWORDS}

animal welfare, animal rights, animal behavior, ethics, ethology, subjective experience

\begin{abstract}
Since the 1970s, scientists studying animal welfare and philosophers writing about animal ethics have worked toward the common goal of understanding and articulating our proper relationship to animals of other species. However, the two groups approached this task using such different concepts, assumptions, and vocabulary that they functioned as two distinct "cultures" with little mutual understanding or communication. Some of the best known ethical writing created barriers for scientists because it tended (1) to focus only on the level of the individual rather than making some decisions at the level of the population, ecosystem or species, (2) to advocate single ethical principles rather than balancing conflicting principles, (3) to ignore or dismiss traditional ethics based on care, responsibility, and community with animals, (4) to seek solutions through ethical theory with little recourse to empirical knowledge, (5) to lump diverse taxonomic groups into single moral categories, and (6) to propose wholesale solutions to diverse animal use practices. Meanwhile, some of the scientists alienated the ethicists by taking the view that suffering and other subjective experiences of animals are not amenable to scientific enquiry, and by the claim that science could "measure" animal welfare as if it were a purely empirical concept. However, other (often less well known) work in animal ethics creates links with animal welfare science and looks to empirical research to help resolve animal ethics issues. Some of this work (1) expresses moral concern about animals using concepts that lend themselves to scientific analysis, (2) attaches value to traditional care for and community with animals, (3) recognizes the importance of empirical analysis for discriminating between good and bad animal use practices, and (4) sees different taxonomic groups as meriting different types and levels of ethical concern. At the same time, animal welfare science has grown more compatible with the approaches used by some ethicists. Some scientists have recognized and tried to clarify the interplay of normative and empirical elements in the assessment of animal welfare, and many are attempting to understand ethically relevant subjective experiences of animals. The increasing convergence of the scientific and philosophical approaches may lead to a more integrated field of study and to a greater awareness that neither empirical information nor ethical reflection can, by itself, answer questions about our proper relationship to animals of other species.
\end{abstract}

\section{Introduction}

According to an old story, a philosopher was walking down a narrow city street when he saw two neighbours quarrelling while leaning out of opposite upper-storey windows. He listened for a few minutes, and then protested: "Gentlemen, stop. You are arguing from different premises." b 
The image of two adjacent but separate worlds is a familiar one for scientists ever since the famous essay of Snow (1959). "The Two Cultures," which argued that the sciences and the humanities constitute separate cultural realms with little mutual understanding or communication. I believe that much recent enquiry into animal welfare and the ethics of animal use has also existed as two separate cultures. Since about 1970, scientists studying animal welfare and philosophers concerned with animal ethics have been working essentially toward the same goal: to provide a framework that will help us understand and articulate our proper relationship to animals of other species, and to translate this understanding into appropriate action. But the scientists and philosophers set about the task with such different ideas, approaches and vocabulary that for nearly 20 years there was surprisingly little communication between the two camps.

In this essay, I attempt to describe the features that kept these two cultures apart. I then explore some signs that bridges are being built between the science and the philosophy, with the result that a more unified field is beginning to emerge. Throughout, I emphasize that we require both empirical knowledge and ethical reflection in order to give adequate answers to questions about the appropriate treatment of animals.

\section{The "two cultures" of animal welfare science and animal ethics philosophy}

Scientists studying the welfare of animals have generally realized that their field began not because of purely scientific interest in the quality of life of animals, but because of public concern about how animals are raised and treated, as articulated by ethicists and social critics.

Nonetheless, animal welfare scientists have been remarkably selective in acknowledging the role of these ethicists and critics. Those working with farm animals, especially in the United Kingdom, readily gave credit to Ruth Harrison (1964). who catalyzed public concern over the treatment of animals on modern farms. However, some of the academic philosophers who followed Harrison, although arguably just as influential, were seen by animal welfare scientists in an entirely different light. In particular, Animal Liberation by Peter Singer (1990, 1st edition 1975) and The Case for Animal Rights by Tom Regan (1983) did a great deal to generate and articulate public concern over animals (see Jaspers and Nelkin, 1992). However, many animal welfare scientists tended either to ignore these works, or they took pains to distance their own work from the ideas of these ethicists.

The lack of acknowledgement was fully reciprocated by the ethicists. For Regan, who looked upon virtually all use of animals as unacceptable, the scientists' efforts to understand and improve animal use practices must have seemed somewhat irrelevant. In fact, Regan's major work on this topic contains a lengthy chapter entitled "Animal Welfare"; it has 28 footnotes, most of them referring to the work of other philosophers but none to the then growing field of animal welfare science (Regan, 1983). Singer occasionally cited animal welfare research, but usually just to support his claims about undue exploitation of animals, sometimes contrary to the scientists' own intentions. For example, a device developed by animal welfare scientists to raise at-risk piglets in as natural a manner as possible (Lewis et al., 1982) was portrayed by Singer (1990, p. 125) as a way of weaning piglets at an abnormally early age in order to increase production at the expense of the animals' welfare.

The resulting lack of communication prevented both groups from achieving their common goal. In order to address ethical concerns about the treatment of animals, the scientists needed ethical reflection to complement their empirical information; and the ethicists needed to ground their arguments in sound knowledge about animals and animal use practices. But instead of seeing their work as complementary, the two groups seldom communicated and rarely acknowledged that the other had any contribution to 
make. Fortunately, the situation is changing because of some welcome developments on both sides of the cultural gap.

\section{Problems and developments in animal ethics philosophy}

For ease of discussion, I will divide recent (i.e., since 1970) philosophical writing on animal ethics into "Type 1" and "Type 2". By "Type 1", I refer to a group of works which, despite ample differences, shared certain characteristics that created barriers for animal welfare scientists. As examples, I will use the two most prominent books (Regan, 1983; Singer, 1990) although a good deal of other writing in animal ethics reflects many of the same features. Under "Type 2", I am grouping together a very diverse body of animal ethics philosophy which, in various ways, opens doors to communication with animal welfare science. Examples include Midgley (1983; 1986), Lehman (1988), Rollin (1990; 1992; 1993a; b; 1995), Preece and Chamberlain (1993), Thompson (1993), and Donovan and Adams (1996) ${ }^{\mathrm{c}}$. In grouping very diverse animal ethics philosophy into two "types", my intention is merely to highlight some ways in which the philosophical efforts relate to the scientific ones, and to emphasize to animal welfare scientists that if they look beyond the familiar Type 1 works, they will find a substantial body of philosophy that is helpful and often compatible with their own efforts.

\subsection{Type 1 animal ethics and the difficulties it created for animal welfare science}

The Type 1 philosophy had six somewhat over-lapping features that created barriers for scientists concerned about the proper treatment of animals.

First, the Type 1 philosophy was rooted in Western liberal individualism which emphasizes equality and sees the individual (person or animal) as the proper focus of moral concern. For Singer (1990), the basic principle was equal consideration of the interests of all sentient beings. Regan (1983) used the principle of equality to argue that rights should be accorded to all animals that he included within the category of "experiencing subjects of a life" (Regan, 1985, p. 23). Thus both systems, although not requiring equal treatment of diverse animals, were derived in some manner by applying the principle of equality at the level of the individual.

In contrast, many scientists (and some dissenting philosophers) consider that a focus on the individual and the principle of equality do not provide an adequate basis for ethical thinking about animals. Scientists often do make ethical decisions at the level of the individual animal (e.g., euthanasia, individual care of farm animals), but in other cases they view the population, ecosystem or species as the appropriate level for decision making. For example, biologists may believe it is right to kill some elephants in order to maintain a healthy population; or they may manage animal habitats in order to preserve a balanced ecosystem; or they may impose special restraints on certain animals in order to preserve a rare species. Many such actions do not follow from (and may conflict with) the principle of equality applied at the level of the individual.

Second, the Type 1 philosophers seemed to view their task as identifying the single ethical principle (for Singer, consideration of interests; for Regan, respecting individual rights) from which correct treatment of animals could be deduced. Even with such complex issues as wildlife management, Regan (1983, p. 356) explicitly rejected invoking competing principles (e.g., "policies that lessen the total amount of harm" to animals) that were not compatible with his rights-based principle.

To many scientists, this focus on a single principle seemed simplistic because decisions about animals often involve different and conflicting principles, all worthy of consideration. In a single decision, we may feel simultaneously that it is important to allow animals to live freely, to minimize animal suffering, to preserve local ecology, to protect rare species, and to allow local people to produce food. These different 
goals often lead to conflicts, and how to balance the competing claims is a major dilemma in animal management issues. Thus to many scientists and others, Type 1 thinking seemed not to solve, and at times not even to acknowledge, the central task of balancing competing principles and approaches.

Third, Type 1 philosophy emphasized justice for animals, and in some cases respect for animals, but gave little attention to caring for animals. Singer (1990) made it clear that his concern about animals arose from a desire to see ethical principles properly applied, not from any particular interest in or attachment to animals themselves. Regan's system, with its strong focus on respect for the autonomy of animals, attached no value at all to the care of animals in agriculture; and even pet-keeping (which emphasizes care over autonomy) could be seen as ethically suspect within Regan's system. In contrast, the work of animal welfare scientists was strongly oriented toward animal care in the form of improved housing, disease prevention, analgesia, and so on.

Fourth, the Type 1 philosophers displayed great attention to logical consistency but little attention to empirical knowledge or technical analysis. For example, Regan claimed that his policy of non-interference in the lives of wild animals (Regan, 1983, p. 359) would support efforts to preserve endangered species, apparently without realizing that many endangered species are believed to require human interference if they are to survive, even to the point that many members of competing species may have to be killed to protect a few members of rare species (e.g., Marks, 1996). Singer (1990) made more use of technical information about agriculture and biomedical research, but often in a manner that scientists saw as inappropriate (e.g., Russell and Nicoll, 1996). For example, having stated that the balance of suffering vs. pleasure was his criterion for ethical decisions, Singer then gave a description of animal agriculture that emphasized the suffering caused by human callousness but almost completely ignored the prevention or relief of suffering provided by human care. Thus, his use of information appeared to many animal welfare scientists as more rhetorical than analytical.

Fifth, Type 1 philosophy tended to lump very diverse taxonomic groups together as "animals" and to discuss their moral standing as a largely undifferentiated class. Regan's system hinged on identifying "experiencing subjects of a life" (Regan, 1985, p. 23), a group which would include at least all mentally normal mammals aged one year or more (Regan, 1983). For Singer (1990), the critical distinction was between sentient and non-sentient beings, and he proposed that the line fell somewhere near the molluscs. In theory, Singer's system was more sensitive than Regan's to differences between taxonomic groups in that it required respect for the "interests" of sentient beings, and Singer acknowledged that interests vary from taxon to taxon. In practice, however, Singer focused mainly on the aggregate and paid little attention to taxonomic differences, proposing, for example, that consumers refuse to purchase products that have been "tested on animals" (Singer, 1990, p. 94). Biological scientists, in contrast, are strongly focused on taxonomic differences, and often view such differences as ethically significant in animal use decisions. For example, scientists have proposed the use of domestic pigs rather than primates (Orlans et al., 1998), and fish rather than birds or mammals (Huntingford, 1984), as more ethically acceptable ways of conducting certain types of animal research.

Finally, the Type 1 philosophy tended to lump diverse animal use practices together under broad headings such as "commercial animal agriculture", and to advocate extremely general remedies for extremely complex situations. Regan made it clear that his system required not that we replace harmful forms of animal production with more beneficial ones, but that commercial animal production cease entirely. Although Singer's system was potentially more discriminating, in practice Singer also denounced broad categories of animal use in totality, declaring for instance that, "the meat available from butchers and supermarkets comes from animals who were not treated with any real consideration at all while being reared" (Singer, 1990, p. 160). 
Thus, while animal welfare scientists studied specific animal use practices and sought to improve or replace them, the Type 1 thinking seemed to acknowledge little or no scope for solving the ethical problems in such ways.

\subsection{Formulating ethical issues in terms compatible with animal welfare science}

In contrast, a different body of animal ethics philosophy, which I am calling "Type 2", tends to build bridges, or at least to send up flares that are visible from the scientists' side of the abyss.

One encouraging sign is that some common vocabulary is potentially within reach. Many of the concepts used by philosophers have no counterpart in the biological sciences. As long as the philosophers were talking about rights, direct duties, and contracts, while the scientists were talking about stereotypic behaviour, disease incidence, and catecholamine secretion, it was (as Snow put it) as if one group spoke English and the other Tibetan. However, at least some Type 2 philosophy formulates the ethical issues in terms that are more easily incorporated into scientific discourse. The situation, to strain the language metaphor, is more like a South African living in Scotland: the words seem odd, but the meaning can be grasped with a little effort.

\subsubsection{Telos}

One word that scientists can grasp if they try is telos, which Rollin (1992; 1993a) proposed as a term for an animal's genetically encoded "nature". Rollin noted that in human society, we protect key interests of the individual (such as freedom of speech and assembly) because we consider these essential to human nature. Likewise, he states,

"animals, too, have natures - the pigness of the pig, the cowness of the cow . . . which are as essential to their well-being as speech and assembly are to us (Rollin, 1993b, p. 11)

And Rollin proposed that the emerging "social ethic for animals" requires the nurturing and fulfilment of this telos.

In choosing the term telos, Rollin identifies the idea as rooted in the teleological ethics of Aristotle. In Aristotle's system, the telos of an entity is the purpose or function for which it was designed. Thus, the telos of a paddle is to propel a canoe, and a good paddle is one that serves this function well. Extending this idea to animals, pigs and cows were obviously designed by natural selection to function in certain ways, and a good life for such animals could be seen as one that allows them to live in the manner for which they were designed. For example, if we see a calf housed so that it cannot play, or a bird that cannot fly, or a primate that fails to develop normal social attachments, we may feel that the animal is being wrongly treated, not specifically because we think the animal is suffering or unhealthy, but because important elements of its very nature are being denied.

This conception of animal welfare, as Rollin noted, gives science the role of determining the key features that make up the "nature" or telos of an animal. On the surface, scientists have shown little interest in the challenge. To say that animals have a genetically encoded "nature" sounds to many scientists like woolly thinking combined with naive genetic determinism, and the label telos casts further umbrage on the idea because teleological thinking has had a confusing and at times disreputable history in biological thought (Allen and Bekoff, 1995).

Nonetheless, I think we can attach some biological flesh to this philosophical bone. The genetically encoded "nature" of an animal can be seen as including two components: (1) the set of adaptations that 
an animal possesses as a result of its evolutionary history, as modified through domestication and perhaps the animal's own experiences; and (2) the set of genetically encoded instructions that guide the animal's normal ontogenic development (Fraser et al., 1997). If we conceptualize telos in this way, then Rollin's proposal simply means that animals should be allowed to live in a manner for which they are adapted, and to have the type of ontogenic development that is normal for the species. And these two criteria actually form the basis, implicitly or explicitly, of considerable research currently being done by animal welfare scientists. Thus, Rollin's conceptualization of ethical concern for animals provides a promising way of linking animal welfare research with animal ethics philosophy.

\subsubsection{Needs and interests}

For many years, scientists have been struggling to define or conceptualize the "welfare" of animals (e.g., Broom, 1991; Duncan, 1993, 1996; Hurnik, 1993). In a remarkably similar debate, philosophers have tried to articulate the ethical standing of animals, often with reference to animals' "needs" and "interests" (e.g., Feinberg, 1974; Frey, 1980; Regan, 1983; Sapontzis, 1987; Singer, 1990; Rollin, 1992). A full discussion is far beyond my current scope, but a few examples will illustrate that the philosophical discussion has some significant parallels with the scientific one. ${ }^{d}$

Feinberg (1974) proposed that animals have needs in two senses of the word: (1) something required for a function to be performed, such as a car's need for gasoline if it is to run, and (2) something that is good for, and whose lack would be detrimental to, the need holder. To have needs in the second sense, Feinberg argued, an entity must have interests, and this in turn requires cognitive awareness. Thus, the cognitive awareness of animals ultimately causes their needs to be matters of moral concern in a manner that the needs of plants and machines are not. Sapontzis (1987) also used "interests" as a key concept in the moral standing of animals, but he defined interests more specifically in terms of feelings of well-being. Sapontzis noted, for example, that fat people might "need" to lose weight for the good functioning of their bodies, but if they enjoy eating and detest dieting, then their lives might be made more pleasant (although perhaps shorter) by remaining fat. Thus, he noted, "Pursuing good health usually is important for our feelings of well-being, but when that pursuit undermines those feelings, it ceases to be in our interest" (Sapontzis, 1987, p. 119). Regan (1983) proposed that an animal's welfare involves both "preference interests" (things that the animal likes, desires, or dislikes and wants to avoid), and "welfare interests" (things that benefit the animal and contribute to its well-being, whether or not the animal actually wants or desires them).

The different approaches, and the attendant confusion, have obvious parallels in the debate among scientists over how to conceptualize the welfare of animals. For example, Hurnik (1993) pointed out that what an animal desires (roughly, Regan's "preference interests") may not actually be good for it (Regan's "welfare interests"), and he suggested that welfare depends not on the animal's desires but on what it actually needs for survival, health, and comfort. In a contrasting interpretation, Duncan (1993, p. 9) noted that "sentience is a necessary prerequisite for welfare". Therefore, he argued, welfare does not correspond simply to good health, fitness, or lack of stress (roughly, Sapontzis' "needs") because these concepts can be applied to plants or other non-sentient organisms. Rather, welfare refers to what is actually experienced by the animal (roughly, Sapontzis' "interests"); thus, the good functioning of the body will usually but not necessarily promote the animal's welfare.

Most attempts by scientists to conceptualize and study animal welfare boil down to three key issues: that animals should feel well by being free from prolonged or intense fear, pain and other unpleasant states, and by experiencing normal pleasures; that animals should function well in the sense of satisfactory health, growth and normal behavioural and physiological functioning; and that animals should lead natural lies through the development and use of their natural adaptations (Duncan and Fraser, 1997; Fraser et 
al., 1997). These ideas correspond at least roughly to the concepts of "interests", "needs", and telos, respectively, as defined by some of the philosophers. This correspondence provides a reasonable basis for linking empirical research on animal welfare with the issues raised by ethicists as the basis for evaluating our actions with regard to animals.

\subsection{Communitarian and care-based ethics}

Some philosophers have also broadened the basis of animal ethics beyond the logical but abstract formulations of the Type 1 philosophy with its emphasis on individualism, equality, and autonomy. Some have begun to recast animal ethics in ways that value traditional attitudes of caring for and community with animals. Donovan (1996), in a feminist critique of animal rights theory, proposed that the "morality of responsibility" of feminist thinking, with its emphasis on relations and connectedness, provides an alternative to the "morality of rights" of ethicists such as Regan. Similarly, Preece and Chamberlain (1993) suggested that problems of animal ethics require not abstract theory and tightly argued logic, but a return to the sensibility and compassion for animals which, they proposed, is natural to people and has been dulled but not erased by Western civilization. Rollin (1995) suggested that the animal husbandry practices of traditional agriculture protected the interests of animals and worked to the mutual benefit of animals and their keepers. Thus, he called not for an end to animal agriculture, but for a return to a more traditional relationship between agricultural people and the animals in their care.

An ethic based on care and responsibility implies a more communitarian approach to animal issues. ${ }^{\mathrm{e}}$ As noted by Preece and Chamberlain (1993), our intuitions about what is right and wrong in our personal actions often hinge not on treating all others equally, but on our sense of community and shared relationships with others. Midgley (1983) proposed that we see ourselves as members of a number of different communities which create different ethical requirements. Thus, we have responsibilities to immediate family members that we do not have to other friends, responsibilities to friends that we do not have to other fellow citizens, and so on. Midgley pointed out that throughout history our various communities have typically included animals as well as humans: animals we treat as family members, those we rear on our farms, those whose lives we affect in other ways. To each of these, we feel quite different kinds and degrees of responsibility depending on how we affect and interact with them. Callicott (1989, p. 56) carried the idea further by proposing that the natural world - the "biotic community" - can be viewed as another such multi-species community to which we belong and within which we have certain responsibilities.

\subsection{Recognizing the complexity of animal ethics issues and the need for empirical knowledge}

Unlike Type 1 philosophers who tended to advocate wholesale remedies based on minimal technical analysis, some philosophers have argued that empirical knowledge and technical analysis are essential to properly assess and act on animal ethics issues. As noted above, Rollin (1993a) emphasized that his approach to animal ethics requires empirical understanding of animals for its implementation. Thompson (1993, p. 47) noted that even using the criteria of certain Type 1 philosophers,

"Current animal production systems can be evaluated only when ... questions of impact upon animals have been answered, either through empirical research or through philosophy (and most likely through a combination of both.)"

In a similar vein, Lehman (1988) criticized the claim that abolishing domestic animal production would lead to greater availability of food for people, as proposed by Gruzalski (1983) and others; in reality, Lehman suggested, this is a complex empirical question whose answer will vary from one agricultural system to another. Likewise, Blatz (1991, p. 486) proposed that some of the conclusions of the Type 1 
philosophers need careful technical evaluation, and he urged his fellow philosophers not to act "as though, operating alone, philosophers can settle questions requiring complex empirical inputs."

As one aspect of this appreciation of empirical knowledge, some philosophers have moved away from lumping diverse animal species into simple moral categories such as 'sentient' vs. 'non-sentient', or 'rights-holders' vs. 'non-rights-holders'. For example, Rachels (1989) proposed that our various human rights depend on the human species having certain attributes, and that we should ascribe similar rights to other species depending on whether the species share these same attributes. For instance, Rachels (1990) suggested that the value we attach to human life depends on a person being alive not only in the biological sense but in the "biographical" sense of having activities, friendships, and so on. Rachels argued that the value of animal life likewise depends on the degree to which the animal has a "biographical" life. Thus, Rachels suggested that the moral objection to killing animals need not be an "all-or-nothing" matter. Rather, killing would be of greatest concern in the case of animals that have rich, experiential lives, live in organized social groups, and form bonds with their relatives. Killing would be a less severe concern, but not necessarily trivial, for animals whose capacity for such a life is more limited. As Rachels (1989, p. 123) noted, this approach will "avoid the trap of lumping all non-human animals together".

\subsection{Implications of Type 2 philosophy for animal welfare science}

Some of the Type 2 philosophy has important implications for animal welfare science. The empirical orientation of Rollin, Thompson, Blatz and others creates an obvious need for science to assess the likely outcomes of possible changes in animal use practices. To meet this need, however, will entail an expansion of the typical boundaries of animal welfare science. To date, animal welfare scientists have typically tried to assess relatively minor changes in animal use practices, asking, for example, whether sows are better off in pens or in stalls. Ethicists have typically raised much broader issues by advocating, for example, the elimination of entire systems of animal production or the wholesale replacement of animal production with crop production. These broader issues also require technical analysis of the likely effects on both animals and humans. Without such analysis, well-motivated people may be persuaded to take actions whose consequences they would neither anticipate nor endorse.

An ethic of animal use that takes account of the characteristics and capacities of different animal species requires substantial understanding of the behaviour, biology, and psychology of animals. In the past, increased knowledge of animals, especially from the study of animal behaviour, has helped to increase the general level of public sensitivity to animals (Jamieson, 1993; Preece and Chamberlain, 1993; Bekoff, 1994). For example, Dunlap (1988) describes how the scientific study of wolves - their social behaviour, communication, and role in ecological systems - contributed to a public that was more sympathetic to the conservation and welfare of the animals. However, the ethical ideas of Rollin and Rachels, described above, have more specific requirements for knowledge about animals' natural behaviour, emotions, cognitive processes, and awareness, and of how these vary between taxonomic groups.

Communitarian and care-based approaches to animal ethics tend to expand animal welfare science to include the field of human-animal relations. Understanding and articulating the types of community we have with other species is an important step in working out our responsibilities to them (see Thompson, 1993). As Midgley (1983, p. 111) noted:

"It is one of the special powers and graces of our species . . . to draw in, domesticate and live with a great variety of other creatures. No other animal does so on anything like so large a scale. Perhaps we should take this peculiar human talent more seriously and try to understand its workings." 
Finally, communitarian thinking, extended by Callicott's view that our duties within the "biotic community" depend on our ecological relationships, encourages animal welfare science to expand in ecological directions as well. Harm to animals on a large scale results from human interference with ecological processes through agriculture, forestry, transportation, urbanization, and probably most forms of economic activity. Type 1 philosophy has generally focused on our direct and intentional actions toward animals; thus, it condemns animal production, where effects on animals are direct and deliberate, but has little to say about crop production, where many of the adverse effects on animals are unintended. However, our indirect and unintended actions may have enormous effects on animals. For example, of the bird species driven to extinction by human actions, intentional killing was involved in only a small minority, the remainder being exterminated unwittingly by disturbances to habitat or to the balance of nature (Mackenzie, 1977).

Moreover, our unintended actions may have drastic effects on animal welfare precisely because these effects tend to be ignored and uncontrolled. In one of the few well-documented examples, Nass et al. (1971) used radio telemetry to follow the fate of Polynesian rats in a sugar plantation when sugar cane was harvested by machine. The majority of the rats in the plantation were fatally wounded by the harvesting machinery, or they died of suffocation when their burrows were compacted; most of the remainder died within a few days from injuries or predation after their cover was destroyed. One tenacious but unlucky rat was buried for a day and a half until it burrowed into a windrow of sugar cane where it was picked up by a machine, deposited in a pile, loaded into a truck, driven to a mill, and placed in a washer.

This is just one exotic example of the huge impact we have on animal welfare in unintended ways, often by actions directed at the population or eco-system level through wildlife management, pest control, and various land use activities. To mitigate these effects will require extensive empirical understanding. It will also require an expanded ethical framework that is broad enough to encompass unintentional effects as well as intentional ones, and that provides workable guidance on how to balance decisions made at the population and eco-system level with those made at the level of the individual animal (Marks, 1996).

\section{Problems and developments in animal welfare science}

While these developments were occurring in animal ethics philosophy, certain changes in animal welfare science were making the scientific activity more compatible with the ideas of the ethicists.

\subsection{Conceptualizing animal welfare to incorporate values}

One feature of animal welfare science that distanced it from animal ethics philosophy was the scientists' apparent failure to recognize the normative or value-related dimension of animal welfare research. Being more comfortable with empirical concepts than with normative ones, some scientists spoke about "measuring" animal welfare as if it were a purely empirical property such as viscosity or metabolisable energy (Fraser, 1995), and some claimed that empirical questions about animal welfare could be asked independently of ethical considerations (Tannenbaum, 1991). In some such cases, I think the scientists were simply trying to make the valid point that scientific knowledge by itself cannot answer ethical questions. As ethicists and others pointed out, however, animal welfare is inherently a normative concept (Hurnik and Lehman, 1988; Tannenbaum, 1991; Rollin, 1993a,b, 1995); a greater or lesser degree of welfare inherently implies something better or worse for animals, and any assessment of animal welfare is underlain by value notions of what makes for a better or worse life for animals. Hence, the claim that animal welfare can be studied objectively made some ethicists believe that the scientists had fundamentally misconstrued the task. 
This issue has now been reworked by a number of scientists (Hurnik, 1993; Mason and Mendl, 1993; Bekoff, 1994; Fraser, 1995.. My preferred approach can be clarified by considering the following three statements that might be made about a fixture of North American cuisine: sliced white bread.

(1) 'This bread contains less than $1 \%$ fibre,' is a descriptive statement which provides empirical information about the subject.

(2) 'This bread is appalling,' is an evaluative statement, (reflecting what I have called 'preference values' - Fraser, 1995., indicating what we consider better or worse, important or unimportant, desirable or undesirable, but without making specific claims about ethical responsibilities.

(3) 'People should not buy this bread,' is a prescriptive statement (reflecting what I have called 'ethical values') indicating how certain moral agents ought to act.

Faced with such a combination of empirical and normative claims, we sometimes create an 'evaluative concept' such as bread quality. To assess the quality of a bread, we need empirical information about (for example) its composition, freshness, and digestibility; but underlying the empirical study are preference values about what makes bread better or worse - that is, about what is relevant in assessing the quality of bread. Thus, an evaluative concept organizes the empirical information within a framework of preference values, but without making ethical claims about what ought to be done and by whom.

I think we can view animal welfare as an evaluative concept of this type (with the provision that the study of animal welfare is at least partly an attempt to understand the animal's own perceptions of its quality of life). Animal welfare encompasses many variables that can be studied scientifically and objectively. However, our decisions about which variables to study, and how to interpret them in terms of an animal's welfare, involve normative judgements about what we consider better or worse for the quality of life of animals. The resulting assessment of an animal's welfare will presumably influence, but does not by itself determine, our ethical decisions about how animals ought to be treated. Viewing animal welfare in this way allows us to acknowledge the inherent role of values in the study of animal welfare, while still recognizing that scientific study alone cannot answer ethical questions about animal use.

\subsection{Asking the idle question}

A second feature that distanced animal welfare science from animal ethics philosophy was the refusal of some scientists to accept the emotions and other subjective experiences of animals as legitimate topics for scientific enquiry (Rollin, 1995). Many ethicists attach particular importance to the subjective experiences of animals, especially whether animals are suffering or are being deprived of the normal pleasures of life. Many scientists, however, adopted a position described by Tinbergen (1951, p. 4):

"Because subjective phenomena cannot be observed objectively in animals, it is idle either to claim or to deny their existence."

This view was by no means unanimous among scientists (Burkhardt, 1997; Fraser and Duncan, 1998), yet it dominated the scientific study of animal behaviour for several decades. Thus, the questions that were seen as most important by the ethicists were often neglected, or even dismissed as unscientific, by many scientists.

Actually, Tinbergen's position departed sharply from that of earlier ethologists and comparative psychologists who saw the subjective experiences of animals as crucial to understanding their behaviour (Rollin, 1990; Burkhardt, 1997). Among psychologists, for example, William McDougall_1926. proposed that much animal behaviour is caused by the animal experiencing emotions such as fear, sexual desire 
and maternal tenderness. Around this principle, McDougall built a highly influential theory of psychology which was displaced about 1930 by the rising tide of Behaviourism (Murphy and Kovach, 1972). Among ethologists, Julian Huxley (1914, quoted by Burkhardt, 1997, p. 8) proposed that through the objective study of behaviour,

"We can deduce the bird's emotions with much more probability of accuracy than we can possibly have about their nervous processes."

The shift away from including subjective experience in the study of behaviour was a descendant of Positivism (Rollin, 1990), a school of thought that attempted to create a clear separation between science and metaphysics by maintaining that science deals with the material world, not with immaterial spirits or metaphysical entities (see Kolakowski, 1968). With this emphasis on the tangible, Positivist thinkers held that we should not postulate unobservable processes to explain observable ones, and that processes that cannot be observed fall outside the realm of scientific enquiry. Under this influence, the emotions, feelings and other mental states of animals were often banished as explanatory concepts or even as topics for scientific investigation. Hence, what had been the study of the mind or psyche of animals (comparative psychology) and the character or ethos of animals (ethology) became redefined more narrowly as the study of observable behaviour. ${ }^{\dagger}$

In the past 20 years, the Positivist constraints on the study of animal behaviour have been criticized both by philosophers (Midgley, 1983; Rollin, 1990) and by scientists (Dawkins, 1990; Griffin, 1992) through arguments that I will not attempt to summarize here. Animal welfare science has played a pioneering role in the associated revival of interest in the subjective experience of animals (e.g., Thorpe, 1969; Duncan, 1970; Wood-Gush, 1973; Dawkins, 1977, 1980), and some non-applied scientists have joined in the effort. Recently, for example, Burghardt (1995) proposed that the four themes of ethological research as set out by Tinbergen (1963) - causation, function, ontogeny and evolution - be expanded to include (once again) the subjective experience of animals.

This renewed willingness to entertain questions about the subjective experience of animals makes science far more relevant to the concerns of the ethicists, but we need to be clear about what this change entails. First, to propose that the preferences, vocalizations, and physiological changes of animals can shed light on their subjective experience, is not the sort of hypothesis that can be proven or refuted. Rather, it is closer to a research "strategy" or "stance" in the sense of Dennett (1987): a conceptual framework that we adopt to interpret observations and guide further empirical study. Consequently, we will not have the comfort of "falsifying" the strategy of the Positivists or of "proving" the new strategy to be correct. Instead, the non-Positivist strategy of animal welfare science will ultimately be judged (in a scientific context) by its usefulness in suggesting interesting questions, in leading to correct predictions, and in providing satisfying explanations for events.

Second, as we give up the old Positivist criteria for distinguishing science from non-science, new criteria will be needed. The Positivist stance imposed a certain discipline on behavioural science. It helped to prevent scientists from engaging in unrestrained mentalistic speculation, from assuming that the subjective experiences of non-humans are the same as those of humans, and from believing that behaviour is explained when it is merely rephrased in mentalistic terms. These errors are often made by writers purporting to describe the subjective lives of animals (e.g., Thomas, 1994; Masson and McCarthy, 1995), and scientists will need to be clear on the criteria for distinguishing gratuitous speculation from serious attempts to understand the subjective experiences of other species.

Third, to develop and test theories about the subjective states of animals will be an enormous task, and I suspect it will be accomplished only if it engages a wide range of ethologists, comparative psychologists, 
and others. Securing the involvement of such (non-applied) scientists may in itself be a challenge. Whereas animal welfare scientists often study behaviour and physiology in order to understand animals' subjective states, most ethologists and psychologists have been taught that explaining behaviour is their ultimate aim. Hence, to engage non-applied scientists in the task, we will have to be clear on how theories that include animals' emotions and awareness improve on existing explanations of animal behaviour. ${ }^{9}$

Some guidance is provided by Baenninger (1990, p. 257) who used a description of the behaviour of a hungry dog to comment on the reluctance of psychologists to postulate expectation in animals:

"Positive or negative reinforcement may be adequate to explain a dog's movement to a place where food ... has previously occurred. But what of the responses that were not even present during the acquisition trials? Why does the dog perk up its ears, whimper, turn its head and eyes toward the learned location, and prepare to spring toward it? These responses appear only on subsequent trials, and persist into extinction trials."

As Baenninger suggested, we could postulate a number of stimulus-response chains of acquisition for each of these movements, but it would be simpler and less cumbersome to postulate a single mediating mental event called expectation, which influences behaviour in certain ways. As long as we confine ourselves to general trends, such as the fact that food-deprived dogs return to locations where they are habitually fed, then explanations are not likely to be improved by postulating that dogs feel hunger and expect food. But as Baenninger's example shows, when we try to explain why a particular dog responds in a particular, detailed manner, then the inclusion of subjective states in our explanations may be scientifically useful. Hence, the study of individual reactions and behavioural nuances may provide a useful approach for understanding the subjective lives of animals and an impetus for developing theories that include subjective experience.

\section{Animal welfare science and the ethics of animal use: an integrated field?}

The developments described above suggest that we have begun to move away from two separate cultures, one rooted in science and the other in philosophy, and gradually toward a more integrated field encompassing animal welfare science and the ethics of animal use. By an integrated field, I do not mean that workers will be equally conversant with the scientific and philosophical aspects, nor that disagreements about our proper relationship to other species will be resolved. The arguments will continue, but the premises will be closer together.

The process, however, still requires significant developments from both sides. From scientists, we need continued efforts to improve our understanding of animals' emotions, awareness and other subjective experiences, and of how the capacity for these subjective states varies between taxonomic groups; from philosophers, we need ethical ideas that better incorporate species differences to replace crude views of "animals" as an undifferentiated moral category. From scientists, we need a better understanding of the often unwitting effects we have on animal welfare through actions at the population and eco-system level; from philosophers, we need ethical theory that encompasses our full range of effects on animal welfare, the unintended as well as the intended, and those applied at the ecological level as well as those applied at the individual level. From scientists, we need continued research to improve animal care and to understand the forms of community that we create with animals; from philosophers, we need better developed theories that articulate the ethical significance of care and community involving other species. 
${ }^{a}$ It is great honour to give this lecture in memory of David Wood-Gush. In 1971, David Wood-Gush and the late Prof. Frank Elsley jointly obtained a grant to create a research position in farm animal behaviour at the then Edinburgh School of Agriculture, and I had the immense good fortune to be hired. David, from his position in the Poultry Research Centre, took me under his wing. As a mentor and senior colleague, he was simply exemplary - always available, supportive, generous, and full of good humour.

${ }^{b}$ David Wood-Gush was also the most adroit punster I ever knew. About 1973, David was telling me about an American woman who was in the news for her behind-the-scenes activities for African-American rights. I happened to ask if she was part of the group called Black Power. "Not quite," he replied, "more of a gray eminence." I would like to propose that future Wood-Gush Memorial Lecturers make an effort to perpetuate David's tradition of the strained but erudite pun.

${ }^{\mathrm{c}}$ In addition to the philosophers whose ethical thinking is more compatible with animal welfare science, several philosophers have written specifically about the scientific study of animal welfare, especially to help clarify the involvement of values in animal welfare research. Examples include Tannenbaum (1991), Sandøe and Simonsen (1992), Rollin (1993a; b; 1995) and Stafleu et al. (1996).

d As this discussion illustrates, "interests" was an important concept in the Type 1 philosophy as well. For Singer and Regan, however, claiming that animals have interests was largely a first step in establishing that animals are entitled to moral consideration within the ethical systems that those authors proposed. Thus for Regan, claiming that animals have interests was a basis for claiming that they have rights. In contrast, for animal welfare scientists and for philosophers such as Rollin, the issue is not to assert that animals have interests but to understand these interests and to accommodate them in appropriate ways.

e For a general introduction to communitarian and care-based ethics, see Beauchamp and Childress (1994), especially pp. 77-92.

${ }^{f}$ Positivism had a second and more subtle influence on the study of behaviour. Positivist thinking included the notion that the sciences are built upon each other in a hierarchical structure of knowledge (Lenzer, 1975). Thus, Auguste Comte considered that sociology rests on physiology, which rests on chemistry, which rests on physics. Within this mind-set, the behaviour of animals was seen as ultimately explainable in terms of physiological processes. When physiological processes cause their outward manifestations that we call behaviour, perhaps the animal does experience some agreeable or disagreeable feeling, but the subjective experience is merely an epiphenomenon that accompanies, but in no sense causes, the performance of the behaviour. Thus, T.H. Huxley (quoted by William James et al., 1890, p. 131) proposed that the consciousness of animals is merely, "a collateral product of its working, . . . as completely without power of modifying that working as the steam-whistle which accompanies the work of a locomotive engine is without influence on its machinery." According to this view, the subjective experiences of animals not only fall outside the realm of scientific study as Tinbergen proposed, they are also unimportant because they play no role in causing events in the real world.

${ }^{g}$ In this respect, the study of behaviour may be at a stage similar to that of physics a century ago when different types of theories were competing to explain physical phenomena. Scientists in the Positivist tradition tried to explain physical and chemical processes without reference to unobservable entities such as atoms (Feigl, 1995), and these efforts died out only when the atomic theory of matter was well enough developed to produce explanations and predictions that could not be generated by other theories. 


\section{Acknowledgements}

I am indebted to Ed Pajor, Joy Mench, Phillip Scarpino, David Morton and Paul Hemsworth for kindly bringing relevant literature to my attention, and to Dan Weary for helpful comments on the manuscript. As always, I am grateful to my many colleagues at the former Centre for Food and Animal Research in Ottawa for their support and encouragement in preparing this material and throughout our many years of working together.

\section{References}

Allen, C., Bekoff, M., 1995. Function, natural design, and animal behavior: philosophical and ethological considerations. In: Thompson, N.S. _Ed.., Perspectives in Ethology, Vol. 11 (Behavioral Design). Plenum, New York, USA, pp. 1-46.

Baenninger, R., 1990. Consciousness and comparative psychology. In: Johnson, M.G., Henley, T.B. (Eds.), Reflections on the Principles of Psychology: William James After a Century. Erlbaum, Hillsdale, USA, pp. 249-269.

Beauchamp, T.L., Childress, J.F., 1994. Principles of Biomedical Ethics, 4th edn. Oxford Univ. Press, New York, USA.

Bekoff, M., 1994. Cognitive ethology and the treatment of non-human animals: how matters of mind inform matters of welfare. Anim. Welfare 3, 75-96.

Blatz, C.V., 1991. Why_most. humans are more important than other animals. In: Blatz, C.V. _Ed.., Ethics and Agriculture. University of Idaho Press, Moscow, USA, pp. 478-487.

Broom, D.M., 1991. Animal welfare: concepts and measurement. J. Anim. Sci. 69, 4167-4175.

Burghardt, G.M., 1995. Brain imaging, ethology, and the non-human mind. Behav. Brain Sci. 18, 339340.

Burkhardt, R.W., Jr., 1997. The founders of ethology and the problem of animal subjective experience. In: Dol, M., Kasanmoentalib, S., Lijmbach, S., Rivas, E., van den Bos, R. (Eds.), Animal Consciousness and Animal Ethics. Van Gorcum, Assen, The Netherlands, pp. 1-13.

Callicott, J.B., 1989. In Defense of the Land Ethic. State University of New York Press, Albany, USA.

Dawkins, M.S., 1977. Do hens suffer in battery cages? Environmental preferences and welfare. Anim. Behav. 25, 1034-1046.

Dawkins, M.S., 1980. Animal Suffering. Chapman \& Hall, London, UK.

Dawkins, M.S., 1990. From an animal's point of view: motivation, fitness, and animal welfare. Behav. Brain Sci. 13, 1-9, 54-61.

Dennett, D.C., 1987. The Intentional Stance. MIT Press, Cambridge, USA.

Donovan, J., 1996. Animal rights and feminist theory. In: Donovan, J., Adams, C.J. (Eds.), Beyond Animal Rights: A Feminist Caring Ethic for the Treatment of Animals. Continuum, New York, USA, pp. 34-59.

Donovan, J., Adams, C.J._Eds.., 1996. Beyond Animal Rights: A Feminist Caring Ethic for the Treatment of Animals. Continuum, New York, USA.

Duncan, I.J.H., 1970. Frustration in the fowl. In: Freeman, B.M., Gordon, R.F. (Eds.), Aspects of Poultry Behaviour. British Poultry Science Ltd., Edinburgh, UK, pp. 15-31.

Duncan, I.J.H., 1993. Welfare is to do with what animals feel. J. Agric. Environ. Ethics 6 (Suppl. 2), 8-14.

Duncan, I.J.H., 1996. Animal welfare defined in terms of feelings. Acta Agric. Scand. Sect. A, Anim. Sci.Suppl. 27, 29-35.

Duncan, I.J.H., Fraser, D., 1997. Understanding animal welfare. In: Appleby, M.C., Hughes, B.O. (Eds.), Animal Welfare. CAB International, Wallingford, UK, pp. 19-31.

Dunlap, T.R., 1988. Saving America's Wildlife: Ecology and the American Mind, 1850-1990. Princeton Univ. Press, Princeton, USA. 
Feigl, H., 1995. Positivism and Logical Empiricism. In: The New Encyclopedia Britannica, 15th edn., Vol. 25. Encyclopedia Britannica, Chicago, USA, pp. 630-636.

Feinberg, J., 1974. The rights of animals and unborn generations. In: Blackstone, W.T. (Ed.), Philosophy and Environmental Crisis. University of Georgia Press, Athens, USA, pp. 43-68.

Fraser, D., 1995. Science, values and animal welfare: exploring the 'inextricable connection'. Anim. Welfare 4, 103-117.

Fraser, D., Duncan, I.J.H., 1998. "Pleasures", "pains" and animal welfare: toward a natural history of affect. Anim. Welfare 7, 383-396.

Fraser, D., Weary, D.M., Pajor, E.A., Milligan, B.N., 1997. A scientific conception of animal welfare that reflects ethical concerns. Anim. Welfare 6, 187-205.

Frey, R.G., 1980. Interests and Rights: The Case Against Animals. Clarendon Press, Oxford, UK.

Griffin, D.R., 1992. Animal Minds. University of Chicago Press, Chicago, USA.

Gruzalski, B., 1983. The case against raising and killing animals for food. In: Miller, H.B., Williams, W.H. (Eds.), Ethics and Animals. Humana Press, Clifton, USA, pp. 251-265.

Harrison, R., 1964. Animal Machines. Vincent Stuart, London, UK.

Huntingford, F.A., 1984. Some ethical issues raised by studies of predation and aggression. Anim. Behav. 32, 210-215.

Hurnik, J.F., 1993. Ethics and animal agriculture. J. Agric. Environ. Ethics 6 (Suppl. 1), 21-35.

Hurnik, J.F., Lehman, H., 1988. Ethics and farm animal welfare. J. Agric. Ethics 1, 305-318.

James, W., 1890. The Principles of Psychology, Vol. 1. Reprinted 1950, Dover Publications, New York, USA.

Jamieson, D., 1993. Ethics and animals: a brief review. J. Agric. Environ. Ethics 6 (Suppl. 1), 15-20.

Jaspers, J.M., Nelkin, D., 1992. The Animal Rights Crusade: The Growth of a Moral Protest. The Free Press, New York, USA.

Kolakowski, L., 1968. The Alienation of Reason: A History of Positivist Thought (N. Guterman, translator). Doubleday, New York, USA.

Lehman, H., 1988. On the moral acceptability of killing animals. J. Agric. Ethics 1, 155-162.

Lenzer, G. (Ed), 1975. Auguste Comte and Positivism: The Essential Writings. University of Chicago Press, Chicago, USA.

Lewis, N.J., Hurnik, J.F., Gordon, D.J., 1982. Nursing apparatus for neonatal piglets. Can. J. Anim. Sci. 62, 975-978.

Mackenzie, J.P.S., 1977. Birds in Peril. McGraw-Hill Ryerson, Toronto, Canada.

Marks, C.A., 1996. Do we need a new vertebrate pest control ethic? In: Fisher, P., Marks, C.A. (Eds.), Humaneness and Vertebrate Pest Control. Victorian Department of Natural Resources and Environment, Frankston, Australia, pp. 16-19.

Mason, G., Mendl, M., 1993. Why is there no simple way of measuring animal welfare?. Anim. Welfare 2, 301-319.

Masson, J.M., McCarthy, S., 1995. When Elephants Weep: The Emotional Lives of Animals. Delacorte Press, New York, USA.

McDougall, W., 1926. An Introduction to Social Psychology, Revised edition (First edition 1908). John W.Luce and Co., Boston, USA.

Midgley, M., 1983. Animals and Why They Matter. University of Georgia Press, Athens, USA.

Midgley, M., 1986. Conflicts and Inconsistencies over Animal Welfare (The Hume Memorial Lecture). The Universities Federation for Animal Welfare, Potters Bar, UK.

Murphy, G., Kovach, J.K., 1972. Historical Introduction to Modern Psychology, 3rd edn. Harcourt Brace Jovanovich, New York, USA.

Nass, R.D., Hood, G.A., Lindsey, G.D., 1971. Fate of polynesian rats in Hawaiian sugarcane fields during harvest. J. Wildl. Manage. 35, 353-356. 
Orlans, F.B., Beauchamp, T.L., Dresser, R., Morton, D.B., Gluck, J.P., 1998. The Human Use of Animals: Case Studies in Ethical Choice. Oxford Univ. Press, New York, USA.

Preece, R., Chamberlain, L., 1993. Animal Welfare and Human Values. Wilfrid Laurier Univ. Press, Waterloo, Canada.

Rachels, J., 1989. Why animals have a right to liberty. In: Regan, T., Singer, P. (Eds.), Animal Rights and Human Obligations. Prentice-Hall, Englewood Cliffs, USA, pp. 122-131.

Rachels, J., 1990. Created from Animals: The Moral Implications of Darwinism. Oxford Univ. Press, Oxford, UK.

Regan, T., 1983. The Case for Animal Rights. University of California Press, Berkeley, USA.

Regan, T., 1985. The case for animal rights. In: Singer, P. (Ed.), In Defense of Animals. Harper and Row, New York, USA, pp. 13-26.

Rollin, B.E., 1990. The Unheeded Cry. Oxford Univ. Press, Oxford, UK.

Rollin, B.E., 1992. Animal Rights and Human Morality, Revised edition. Prometheus Books, Buffalo, USA.

Rollin, B.E., 1993a. Animal welfare, science and value. J. Agric. Environ. Ethics 6 (Supplement 2), 44-50.

Rollin, B.E., 1993b. Animal production and the new social ethic for animals. Food Animal Well-Being. Purdue University Office of Agricultural Research Programs, West Lafayette, USA, pp. 37-54.

Rollin, B.E., 1995. Farm Animal Welfare: Social, Bioethical, and Research Issues. Iowa State Univ. Press, Ames, USA.

Russell, S.M., Nicoll, C.S., 1996. A dissection of the chapter "Tools for research" in Peter Singer's Animal Liberation. Proceedings of the Society for Experimental Biology and Medicine 211, 109-138.

Sandøe, P., Simonsen, H.B., 1992. Assessing animal welfare: where does science end and philosophy begin? Anim. Welfare 1, 257-267.

Sapontzis, S.F., 1987. Morals, Reason, and Animals. Temple Univ. Press, Philadelphia, USA.

Singer, P., 1990. Animal Liberation, 2nd edn. Avon Books, New York, USA.

Snow, C.P., 1959. The Two Cultures and the Scientific Revolution. Cambridge Univ. Press, Cambridge, UK.

Stafleu, F.R., Grommers, F.J., Vorstenbosch, J., 1996. Animal welfare: evolution and erosion of a moral concept. Anim. Welfare 5, 225-234.

Tannenbaum, J., 1991. Ethics and animal welfare: the inextricable connection. J. Am. Vet. Med. Assoc. 198, 1360-1376.

Thomas, E.M., 1994. The Tribe of the Tiger. Simon \& Schuster, New York, USA.

Thompson, P.B., 1993. Animals in the agrarian ideal. J. Agric. Environ. Ethics 6 (Supplement 1), 36-49.

Thorpe, W.H., 1969. Welfare of domestic animals. Nature 244, 18-20.

Tinbergen, N., 1951. The Study of Instinct. Clarendon Press, Oxford, UK.

Tinbergen, N., 1963. On aims and methods of ethology. Z. Tierpsychol. 20, 410-433.

Wood-Gush, D.G.M., 1973. Animal welfare in modern agriculture. Brit. Vet. J. 129, 167-174.

${ }^{a}$ It is great honour to give this lecture in memory of David Wood-Gush. In 1971, David Wood-Gush and the late Prof. Frank Elsley jointly obtained a grant to create a research position in farm animal behaviour at the then Edinburgh School of Agriculture, and I had the immense good fortune to be hired. David, from his position in the Poultry Research Centre, took me under his wing. As a mentor and senior colleague, he was simply exemplary - always available, supportive, generous, and full of good humour.

${ }^{b}$ David Wood-Gush was also the most adroit punster I ever knew. About 1973, David was telling me about an American woman who was in the news for her behind-the-scenes activities for African-American rights. I happened to ask if she was part of the group called Black Power. "Not quite," he replied, "more 
of a gray eminence." I would like to propose that future Wood-Gush Memorial Lecturers make an effort to perpetuate David's tradition of the strained but erudite pun.

${ }^{c}$ In addition to the philosophers whose ethical thinking is more compatible with animal welfare science, several philosophers have written specifically about the scientific study of animal welfare, especially to help clarify the involvement of values in animal welfare research. Examples include Tannenbaum (1991), Sandøe and Simonsen (1992), Rollin (1993a; b; 1995) and Stafleu et al. (1996).

"As this discussion illustrates, "interests" was an important concept in the Type 1 philosophy as well. For Singer and Regan, however, claiming that animals have interests was largely a first step in establishing that animals are entitled to moral consideration within the ethical systems that those authors proposed. Thus for Regan, claiming that animals have interests was a basis for claiming that they have rights. In contrast, for animal welfare scientists and for philosophers such as Rollin, the issue is not to assert that animals have interests but to understand these interests and to accommodate them in appropriate ways.

e For a general introduction to communitarian and care-based ethics, see Beauchamp and Childress (1994), especially pp. 77-92.

${ }^{f}$ Positivism had a second and more subtle influence on the study of behaviour. Positivist thinking included the notion that the sciences are built upon each other in a hierarchical structure of knowledge (Lenzer, 1975). Thus, Auguste Comte considered that sociology rests on physiology, which rests on chemistry, which rests on physics. Within this mind-set, the behaviour of animals was seen as ultimately explainable in terms of physiological processes. When physiological processes cause their outward manifestations that we call behaviour, perhaps the animal does experience some agreeable or disagreeable feeling, but the subjective experience is merely an epiphenomenon that accompanies, but in no sense causes, the performance of the behaviour. Thus, T.H. Huxley (quoted by William James et al., 1890, p. 131) proposed that the consciousness of animals is merely, "a collateral product of its working, . . . as completely without power of modifying that working as the steam-whistle which accompanies the work of a locomotive engine is without influence on its machinery." According to this view, the subjective experiences of animals not only fall outside the realm of scientific study as Tinbergen proposed, they are also unimportant because they play no role in causing events in the real world.

${ }^{g}$ In this respect, the study of behaviour may be at a stage similar to that of physics a century ago when different types of theories were competing to explain physical phenomena. Scientists in the Positivist tradition tried to explain physical and chemical processes without reference to unobservable entities such as atoms (Feigl, 1995), and these efforts died out only when the atomic theory of matter was well enough developed to produce explanations and predictions that could not be generated by other theories. 